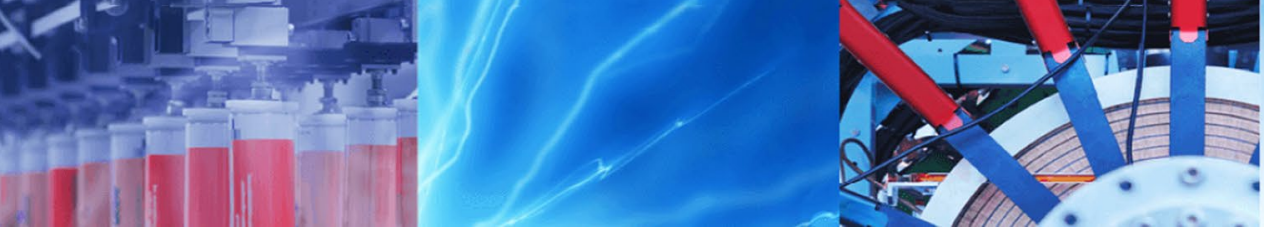

Research Article

\title{
Statistical analysis of acoustic emission signals and tensile deformation measurement for three dimensional carbon fiber braided composites
}

\author{
Wei Zhou ${ }^{1,2} \cdot$ Ya-jing Shang ${ }^{1,2} \cdot$ Peng-fei Zhang ${ }^{1,2} \cdot$ Han-fei Yin ${ }^{1,2} \cdot$ Lian-hua Ma ${ }^{1,2}$
}

Received: 7 April 2020 / Accepted: 12 June 2020 / Published online: 17 June 2020

(c) Springer Nature Switzerland AG 2020

\begin{abstract}
Accurate assessment for mechanical and damage behaviors of three dimensional carbon fiber braided composites by acoustic emission technique is difficult in practical application. In this study, a statistical analysis approach with calculated amplitude spectrum, probability distribution and entropy is proposed to process acoustic emission signals. Moreover, the tensile behaviors and damage characteristics of three dimensional four directional and five directional braided composites are investigated systematically by combining digital image correlation and acoustic emission methods. The results indicate that three dimensional five directional braided composites possess excellent load-bearing and deformation resistibility capacity, owing to more compact preform structure with additional axial yarns. The acoustic emission statistical analysis method can be used as criteria to distinguish and quantify various irreversible damage and failure mechanisms in three dimensional braided composites. Furthermore, the deformation, damage and failure criterion for two types of composites are fully described based on deformation fields and acoustic emission signals.
\end{abstract}

Keywords Three dimensional braided composites · Deformation measurement · Statistical analysis · Acoustic emission . Digital image correlation

\section{Introduction}

Three dimensional (3D) braided composites are advanced composites, which have been increasingly studied and used in numerous fields such as aeronautics, vehicles and energy industries due to a series of excellent mechanical properties like favorable damage tolerance, outstanding fatigue resistance, high load-bearing capacity and low delaminating tendency than the traditional laminate composites [1-3]. Therefore, it is essential to reveal the mechanical behaviors and damage characteristics of $3 D$ braided composites with complicated structures $[4,5]$.

In order to make better utilization of 3D braided composites, the deformation and damage properties under different loading conditions have been studied by numerous researchers. Yan et al. [6] conducted the impact tests on 3D carbon/epoxy braided composites with various braiding angles and it was found that the specimens with larger braiding angles can sustain higher loads and own smaller impact damage zones. Zhai et al. [7] carried out bending mechanical tests on 3D braided composites, and the results demonstrated that bending strength of the specimens decreased with the increase of temperature increment. Furthermore, Li et al. [8] analyzed the damage and failure process of 3D braided T-joints composites under tensile tests. It was found that the damage mainly occurs in glue film zones and the interface of T-joints.

$\bowtie$ Wei Zhou, zhouweihy@126.com; zhouwei@hbu.edu.cn; $\bowtie$ Lian-hua Ma, Ihma@hbu.edu.cn |'School of Quality and Technical Supervision, Hebei University, Baoding 071002, China. ${ }^{2}$ National and Local Joint Engineering Research Center of Metrology Instrument and System, Hebei University, Baoding 071002, China. 
Nevertheless, due to the complicated meso-structure of $3 \mathrm{D}$ braided composites, it is difficult to sufficiently distinguish the damage and failure mechanisms from the traditional mechanical tests alone. Digital image correlation (DIC) is a non-contact optical testing method, which can accurately measure and calculate full-field displacements and strains at the surface of the objects under loading [9-12]. Feissel et al. [13] utilized DIC technique to study damage and rupture of 3D carbon/epoxy composites for detecting the evolution of early local nonlinear damage. Similarly, Zheng et al. [14] measured strain distribution for 3D braided carbon-aramid hybrid composites during tensile loading by DIC method. The surface full-field strain showed that high strain regions were distributed mainly over the yarns, while low strain zones were distributed along the resin. Meanwhile, Acoustic emission (AE) is a dynamic non-destructive testing (NDT) technology that has been successfully applied to detect the crack initiation and evolution of composites in real-time [15-17]. Su et al. [18] conducted a testing to distinguish all sorts of defects inside 3D braided composites by use of AE technology, the results indicated that the energy of $A E$ signals in specimens with various defects were highly different. And the prefabricated defects caused the energy of $A E$ signals increase in a certain corresponding range. Besides, compared with single NDT technology, the complementary method can achieve more comprehensive results. NagChowdhury et al. [19] assessed the damage evaluation in glass fiber reinforced composites during incremental cyclic tensile tests by AE and DIC methods, which offered bright prospects to potentially anticipate the complete failure in composite structures. Hence, the complementary monitoring technology combining $\mathrm{AE}$ and $\mathrm{DIC}$ is more conducive to study the damage process of composites from inside to outside. Nevertheless, the research on the mechanical analysis of 3D braided composites by AE and DIC complementary technique is extremely limited.

In regard to the signal processing, $\mathrm{AE}$ method requires effective calibration and analysis to discriminate between all sorts of damage modes and failure mechanisms [20-22]. Meanwhile, the quantification of irreversible damage is a challenge and crucial aspect to understand the properties of materials, so it is necessary to find ways of quantifying the dynamic behaviors and micro-damage mechanisms [23-25]. Qi et al. [26] studied the randomly microscopic events (RME) of acrylic bone cement materials under pure tension and three-point bending tests. It was demonstrated that $\mathrm{AE}$ statistical analysis approach with calculated amplitude distribution and probabilistic entropy can reveal the evolving process of the damage, which possibly foreshadow the failure of material. Zhou et al. [27] proposed a new method to distinguish multi-scale damage and failure process of fiber composites under mode-II delamination. The results indicated that AE statistical analysis approach reflects the inherent microscopic damage of fiber composites by the calculated amplitude distribution and amplitude spectrum. Kahirdeh and Khonsari [28] carried out numerous cyclic bending fatigue experiments on aluminum metals and glass/ epoxy composites to study the process of micro-structural damage by the analysis of computed acoustic entropy. It was found that the features of acoustic entropy provided valuable damage information and quantified the deteriorations of materials. Thus, the statistical analysis method is effective to distinguish and quantify the history and evolution of micro-structural damage.

In this work, the effects of preform structures on longitudinal tensile behaviors of 3D carbon fiber braided composites were investigated systematically. Meanwhile, a novel statistical analysis method was firstly used for analyzing AE signals to distinguish and quantify the difference of various irreversible damage and failure mechanisms in 3D four directional and five directional braided composites. More importantly, the damage process and failure criteria for two types of composites based on computed deformation fields and AE signals were discussed.

\section{Experimental details and methods}

\subsection{Specimens preparation}

Two kinds of 3D carbon fiber braided composites with different preform structures were fabricated using the carbon fiber yarns (T700-12K) and epoxy resin matrix (TDE-86) through the resin transfer molding (RTM) technique by $3 \mathrm{D}$ braided machine in Jiangnan University. The specifications of two types of 3D braided composites are listed in Table 1.

Besides, Fig. 1 shows the geometry and dimensions of $3 \mathrm{D}$ braided composite specimens. Specimen A and B
Table 1 The specifications of two types of 3D braided composites

\begin{tabular}{llllll}
\hline Type & Preform structure & Pitch length $(\mathrm{mm})$ & $\begin{array}{l}\text { Circumferential } \\
\text { pitch length }(\mathrm{mm})\end{array}$ & $\begin{array}{l}\text { Braiding } \\
\text { angle }\left({ }^{\circ}\right)\end{array}$ & $\begin{array}{l}\text { Fiber } \\
\text { volume frac- } \\
\text { tion (\%) }\end{array}$ \\
\hline A & 3D four directional & $6.5-7.0$ & 4.5 & $30^{\circ}$ & 55 \\
B & 3D five directional & $6.8-7.0$ & 3.8 & $30^{\circ}$ & 55 \\
\hline
\end{tabular}


Fig. 1 The geometry and dimensions of 3D braided composite specimens (a)
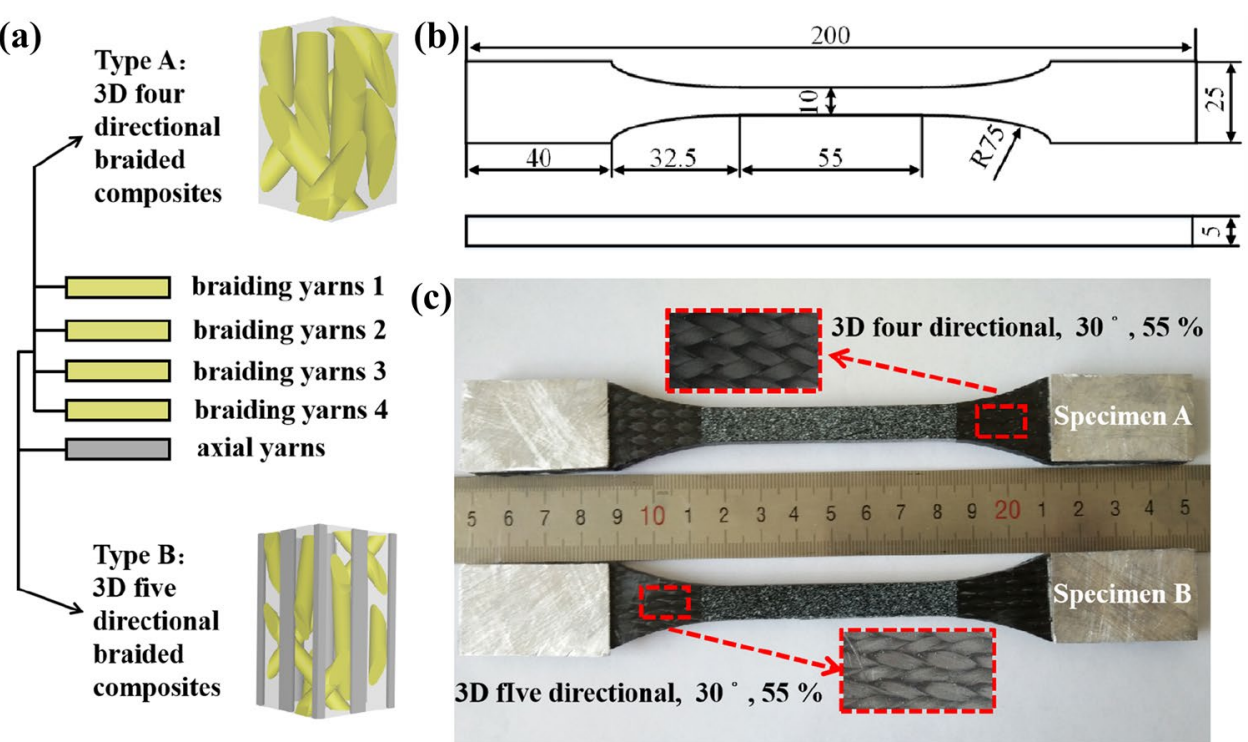

are 3D four directional and five directional carbon fiber braided composites, respectively. Meanwhile, for these two specimens, the average surface braiding angles are $30^{\circ}$, the fiber volume fractions are about $55 \%$ and the thickness of them are $5 \pm 0.2 \mathrm{~mm}$. Moreover, the inner unit cell models of 3D four directional and five directional braided composites are illustrated in Fig. 1a. It can be seen that the unit cell is a cube, which contains four kinds of braiding yarns with different directions for both specimen A and B. Besides, the specimen B has the additional axial reinforced yarns in longitudinal direction. And the interspace between the yarns is filled by matrix. In order to prepare the standard tensile samples, the $3 \mathrm{D}$ rectangular braided composite preforms with the dimensions of $305 \mathrm{~mm} \times 305 \mathrm{~mm}$ were cut into dog bone shape samples with a size of $200 \mathrm{~mm} \times 25 \mathrm{~mm}$ along longitudinal direction by cutting machine according to the ASTM D638 [29], the top and left view of the specimens are shown in Fig. 1b. Owing to the defects around the edge of specimens are inevitable, so the tensile experiments are applied on four samples for each type of preform structures to reduce the error of the cut-edge effect and free-edge effect [30, 31]. Besides, in order to avoid the damage of specimens from clamps, the aluminum stiffeners of size $40 \mathrm{~mm} \times 25 \mathrm{~mm}$ were glued on each side of the specimens. Finally, for purpose of obtaining the surface deformation filed of Specimen $A$ and $B$ during tensile test, black/white speckles were sprayed in the center of specimens along the longitudinal and thickness directions about $70 \mathrm{~mm}$, as depicted in Fig. 1c.

\subsection{Tensile loading}

The tensile experiments of 3D carbon fiber braided composites were conducted on LD26 tensile equipment at room temperature with a constant loading velocity $2 \mathrm{~mm} /$ min according to the standard of ASTM D3039 and GB/T 33613-2017 partly [32, 33]. Meanwhile, the speckle images and $\mathrm{AE}$ signals were acquired by two CMOS cameras (MER500-7UM-L, 2592 pixels $\times 1944$ pixels) and an AE instrument (AMSY-5, Vallen), respectively. The complementary NDT experimental system for tensile experiments is illustrated in Fig. 2.

Two resonant AE senors (VS150-RIC, 100-450 kHz) with $34 \mathrm{~dB}$ inbuilt preamplifier and $150 \mathrm{kHz}$ central frequency were used to record $A E$ signals, whose distance was $70 \mathrm{~mm}$. Silicone grease served as coupling agent, providing for good contact of the sensors and specimens. Moreover, lead-break tests were performed to ensure coupling before the experiments. To sufficiently eliminate mechanical and electrical noise, the threshold and sampling frequency of $A E$ instrument were set to $5 \mathrm{mV}(40 \mathrm{~dB})$ and $5 \mathrm{MHz}$, respectively. Besides, the speckle images in front and side view of the specimens were collected twice every second by CMOS cameras during tensile tests. The deformed images for further analysis were scanned at 38 pixels $/ \mathrm{mm}$ (front) and 35 pixels $/ \mathrm{mm}$ (side).

\subsection{Statistical analysis theory}

The emergence of damage releases much of the energy, which is transmitted in the form of strain waves. 
(a)

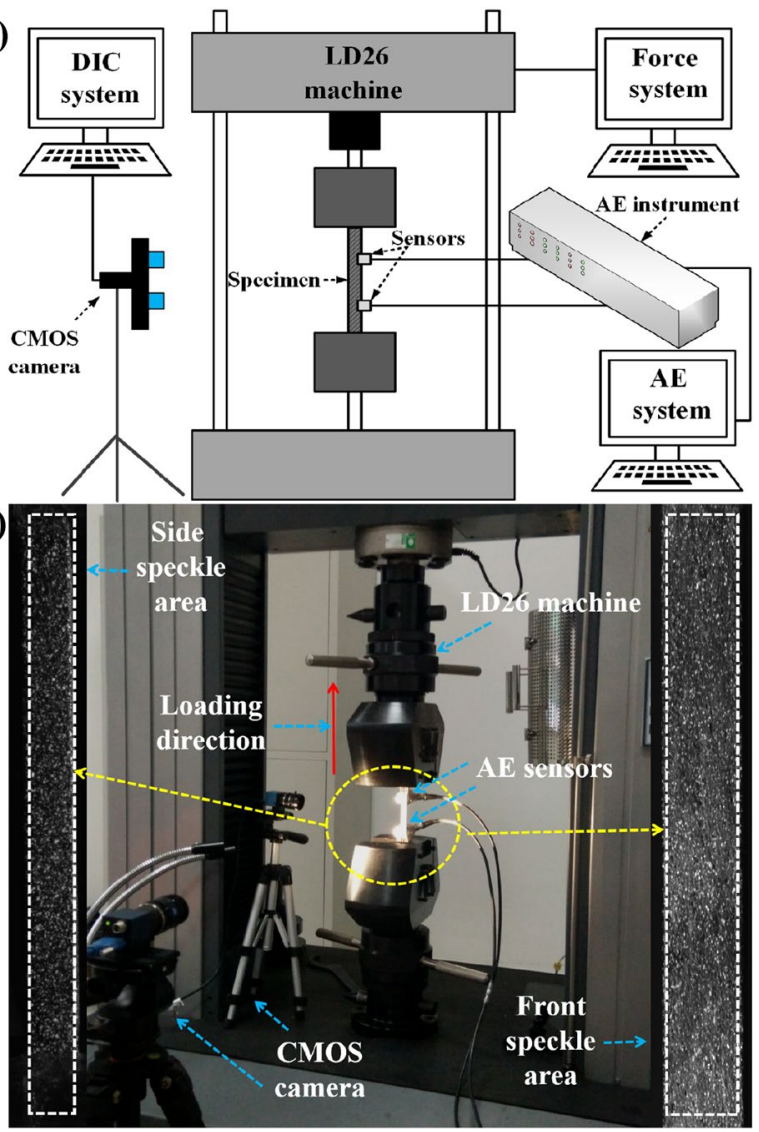

Fig. 2 Complementary NDT experimental system for tensile experiments

Meanwhile, extensive researches have confirmed that the strain waves are closely related to the physical properties of damage. AE technique is usually used to obtain the electrical signals of energy waves, and the corresponding $A E$ signals are parallel to those released energy waves of damage [34, 35]. In order to further characterize and evaluate the dynamic response behaviors and invisible damage characteristics of 3D braided composites, the concept of damage field was proposed. And a multivariate of random damage is defined as a data matrix $D^{A}$ in Eq. (1), which integrates four variables: $M, N, i$, and $j[36,37]$. dependent on the experimental results. In this work, we let the stress levels as the standard of observation window, due to the differences of preform structure for Specimen $\mathrm{A}$ and $\mathrm{B}$. And $i$ is the order of window sequence, $i=1,2$, $3, \ldots, M$. While $N$ is the number of column vectors, which indicates the quantities of sub-intervals that depends on the desired accuracy and the total bandwidth of the $A E$ characteristic parameters like amplitude, energy and other scalable parameters. The AE amplitude has been broadly used for its simplicity in characterization and damage assessment of composites among the acquired AE parameters [38, 39], so we associate the AE amplitude with the stress as the multi-scale criteria to obtain additional knowledge of the damage field. Besides, $j$ is the order of subinterval sequence, and $j=1,2,3, \ldots, N$.

The element $\alpha_{i j}$ is the number of RME from 0 to $i$, whose $\mathrm{AE}$ amplitude drops into $j$ th sub-interval observed according to the measured stress, is expressed as:

$\alpha_{i j}=\sum_{m=1}^{i} x_{m j} \quad i=1,2,3, \ldots, M, \quad j=1,2,3, \ldots, N$

where $x_{i}$ is an event of RME measured in the interval of $(i-1, i)$. So, the amplitude spectrum of RME is defined to describe the trends of the evolving damage state in materials. Moreover, the approximated Gibbs probability is given by:

$p_{i j}=\alpha_{i j} / L_{i j}$

and $L_{i j}$ is to be:

$L_{i j}=\sum_{j=1}^{N} \alpha_{i j}$

Replacing $\alpha_{i j}$ with $P_{i j}$ in Eq. (1), and the expression for probability space matrices of RME $\bar{D}^{A}$ is as follows:

$\bar{D}^{A}=\left[P_{i j}\right]_{M \times N}$

where the element $P_{i j}$ denotes the probability distribution of AE signals, so the probability spectrum of RME $\bar{D}^{A}$ is a form of normalized amplitude spectrum matrix.

$D^{A}=\left\{X_{1}, X_{2}, \ldots, X_{j}, \ldots, X_{N}\right\}=\left\{\begin{array}{c}Y_{1} \\ \vdots \\ Y_{i} \\ \vdots \\ Y_{M}\end{array}\right\}=\left[\alpha_{i j}\right]_{M \times N}=\left[\begin{array}{ccccc}\alpha_{11} & \cdots & \alpha_{1 j} & \cdots & \alpha_{1 N} \\ \vdots & \ddots & \vdots & . & \vdots \\ \alpha_{i 1} & \cdots & \alpha_{i j} & \cdots & \alpha_{i N} \\ \vdots & . & \vdots & \ddots & \vdots \\ \alpha_{M 1} & \cdots & \alpha_{M j} & \cdots & \alpha_{M N}\end{array}\right]$

where $M$ is the number of row vectors, which indicates the total quantities of observation windows that hinges on different time, load, or stress levels, and maximum of $M$ is
The entropy of a continuous probability is employed based on the Gibbs formula $[40,41]$ : 
$S:=\int_{0}^{1} \rho(x) \ln (1 / \rho(x)) d_{x}$

where $\rho(x)$ is the Gibbs probability density function, let $x$ represents an event of the AE amplitude measured on a scale. Moreover, $x=0$ corresponds exactly to the threshold of $\mathrm{AE}$ amplitude, and $x=1$ corresponds exactly to maximum amplitude, so according to $x$ the $N$ subintervals in ascending order used by the detector are $(0,1 / N],(1 / N, 2 / N], \ldots,((N-1) / N, 1]$.

The probability lies in the $j$ th scale sub-interval is $P_{i j}(x)=\int_{(1 / N)(j-1)}^{(1 / N) j} \rho(x) d x$; then we can get $\rho_{i j}(x)=1 /(1 / N)$ $\int_{(1 / N)(j-1)}^{(1 / N) j} \rho(x) d x=N p_{i j}(x)$; and the approximated probability entropy is defined as [42]:

$S \approx \sum_{j=1}^{N}(1 / N) \rho_{i j}(x) \ln \left(1 / \rho_{i j}\right)=\sum_{j=1}^{N} \rho_{i j}(x) \ln \left(1 /\left(N \rho_{i j}(x)\right)\right)$

The minimum possible entropy value equals $\ln (1 / N)$, which is achieved when all RME are in the same scale subinterval. And the maximum possible entropy value equals 0 when all RME equally fall in every scale sub-interval. It is indicate that a greater uncertainty of RME occur with the increase of entropy; and the decreasing entropy means the increasing number of RME occur in few certain scales. The statistical analysis theory based on the calculated amplitude spectrum, probability distribution and entropy of $A E$ signals is applied to 3D braided composites in the section below.

\section{Results and discussions}

\subsection{Mechanical behaviors and damage characteristics}

According to numerous tensile tests for 3D braided composite specimens with two kinds of preform structures, the mechanical behaviors and damage characteristics were acquired. Furthermore, the tensile strength $\sigma_{f}$, which can be calculated by Eq. (8):

$\sigma_{f}=F_{s} / b h$

where $F_{\mathrm{S}}$ is the measured peak load, $b$ and $h$ are the width and thickness of the specimens, respectively. Table 2 shows the peak load and tensile strength for four groups of $3 \mathrm{D}$ braided composite specimens. As we can see, the average peak load and standard deviation of Specimen A are 10.25 and $0.64 \mathrm{kN}$, and those of Specimen B are 38.24 and $1.85 \mathrm{kN}$. Besides, the average tensile strength and standard deviation of Specimen A are 207.01 and $11.41 \mathrm{MPa}$, and those of Specimen B are 777.12 and $50.38 \mathrm{MPa}$. The calculation results indicate that $3 \mathrm{D}$ braided composite specimens have different load-bearing capacity under various preform structures, and Specimen $B$ has much higher peak load and tensile strength than Specimen A.

Moreover, Fig. 3 exhibits tensile stress versus strain curves for 3D braided composite specimens. In the initial loading stage, firstly, the mechanical curves for Specimen $A$ and $B$ look like nearly unchanged, due to the increment rate of stress levels is relatively low. Then, the stress and strain curves for two types of composite specimens increase at a glacial pace. As the loading process keeps on, the curves increase smoothly and exhibit a similar linear relationship, gradually. When the specimens approach to fail, the stress reaches critical value. Afterward, the Specimen $A$ and $B$ fracture completely, the strength and stiffness of specimens decrease significantly, while the stiffness degradation rate of Specimen $B$ is faster. Compared to Specimen $B$, the failure stress of specimen $A$ is obviously lower, and the maximum strain is a little shorter. The results further indicate that the load-bearing capability of Specimen A differs with that of Specimen B, and Specimen $B$ has better strength and enhanced elongation than Specimen $A$. It is because the introduction of axial reinforced yarns helps stabilise the structures in 3D five directional

Table 2 The load and strength for four groups of 3D braided composite specimens

\begin{tabular}{|c|c|c|c|c|c|c|}
\hline \multirow[t]{2}{*}{ Specimen } & \multicolumn{4}{|c|}{ Peak load (kN) } & \multirow[t]{2}{*}{ Average value (kN) } & \multirow{2}{*}{$\begin{array}{l}\text { Standard } \\
\text { deviation } \\
(\mathrm{kN})\end{array}$} \\
\hline & 1 & 2 & 3 & 4 & & \\
\hline A & 10.35 & 9.38 & 10.35 & 10.92 & 10.25 & 0.64 \\
\hline B & 38.24 & 36.83 & 40.86 & 37.04 & 38.24 & 1.85 \\
\hline \multirow[t]{2}{*}{ Specimen } & \multicolumn{4}{|c|}{ Tensile strength (MPa) } & \multirow[t]{2}{*}{ Average value (MPa) } & \multirow{2}{*}{$\begin{array}{l}\text { Standard } \\
\text { deviation } \\
(\mathrm{MPa})\end{array}$} \\
\hline & 1 & 2 & 3 & 4 & & \\
\hline A & 207.00 & 191.43 & 211.22 & 218.40 & 207.01 & 11.41 \\
\hline B & 764.80 & 751.63 & 851.25 & 740.80 & 777.12 & 50.38 \\
\hline
\end{tabular}




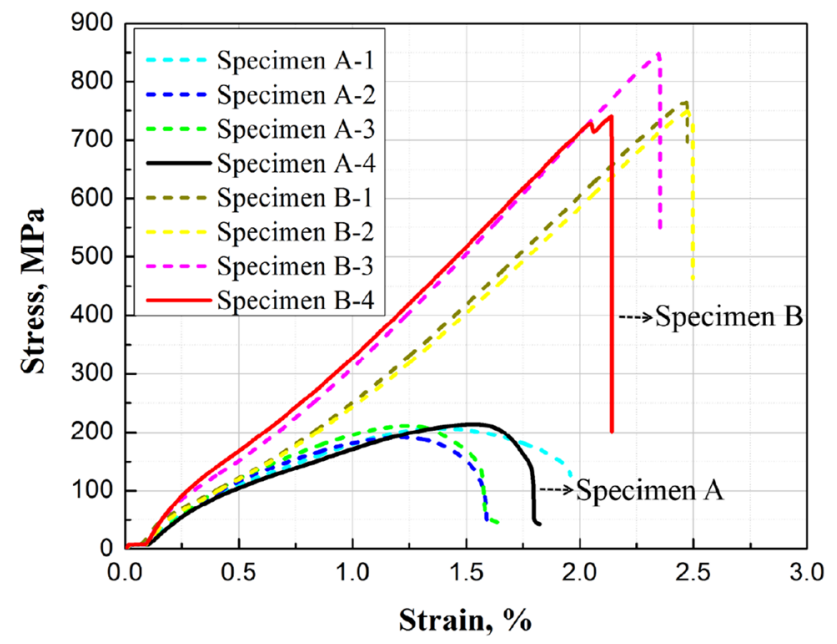

Fig. 3 Tensile stress versus strain for 3D braided composite specimens

braided composites, which strengthens the longitudinal tensile mechanical performances of Specimen B. Besides, the carbon fiber yarns have more excellent tensile strength and stiffness than softer polymer matrix, which take most of the applied load during the tests [43].

It can be found that the four groups of mechanical testing curves for 3D four directional and five directional braided composite specimens have a similar varying tendency. Meanwhile, the 3D braided composite specimens based on RTM technique will inevitably produce defects in manufacturing process, when the permeability of resin is inadequate [44]. The more compact preform structure with additional axial yarns introduction of Specimen $B$ makes it difficult for the resin to infiltrate the fiber well, so the deviation of specimen $B$ is a bit more than the one of Specimen A. While, the deviations of the stress versus strain curves for Specimen A and B are within a certain range. To better know the mechanical behaviors and damage mechanisms of 3D braided composites, two typical Specimen $A$ and $B$ are further studied in the following sections. The maximum stress of Specimen $A$ and $B$ is 218.40 and $740.80 \mathrm{MPa}$, and the maximum strain of them is 1.53 and $2.14 \%$ as shown in Fig. 3.

Figure 4 presents the final damage morphology of typical 3D braided composite specimens under tensile testing. It is clearly seen that the fracture of Specimen A is relatively plane and mainly concentrated on the upper side of the specimen, while Specimen B has a diagonal uneven fracture and the damage regions are in the middle to lower part of the specimen. Therefore, the macro-damage of specimen $B$ is much more obvious than that of specimen A. Moreover, Fig. 5 shows the compositions and structures of $3 \mathrm{D}$ braided composite specimens. It can be seen that an interface of 3D four directional or five directional braided (a)
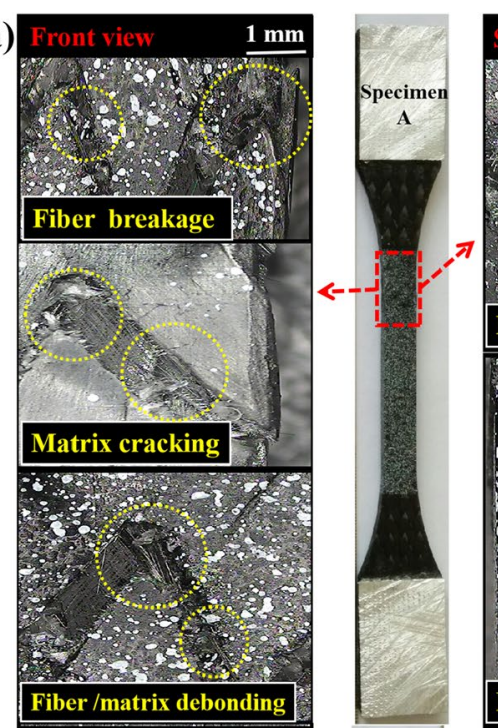

(b)
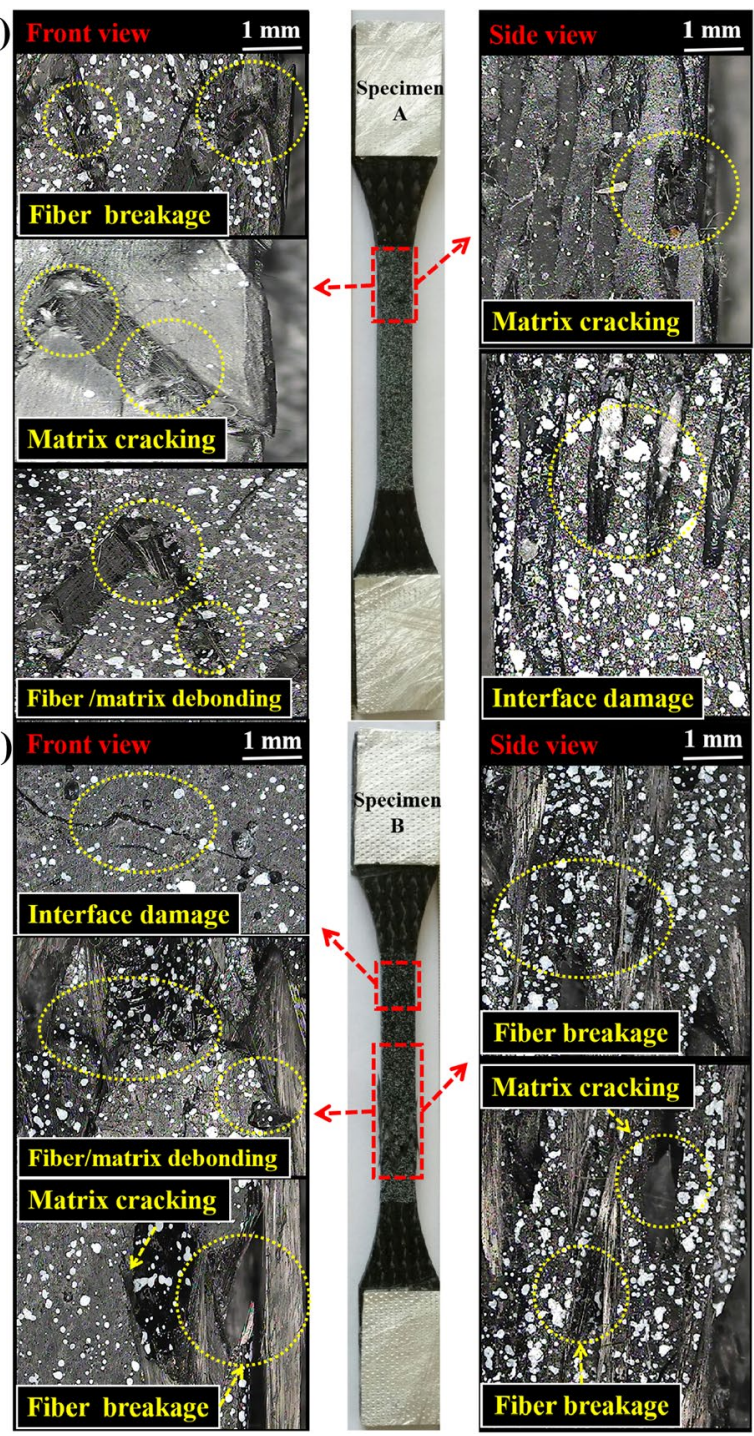

Fig. 4 The final damage morphology of typical 3D braided composite specimens under tensile testing

composite is composed of yarns and out-of-yarn matrix. Besides, the yarn contains a bundle of fibers and their surrounding in-yarn matrix $[45,46]$.

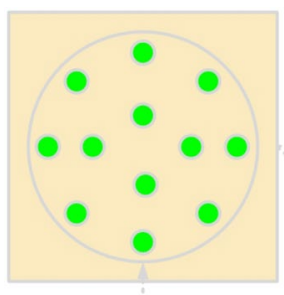

Interface

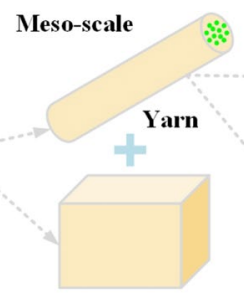

Out-of-yarn Matrix

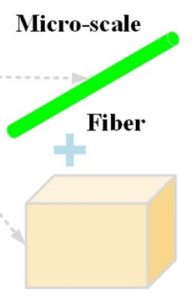

In-yarn Matrix
Fig. 5 The compositions and structures of 3D braided composite specimens 
In order to further understand the meso-scale and micro-scale damage and failure modes of specimens, the two types of fractured composite specimens were further observed by a digital microscope (SK2700P). It can be observed that the damage modes near the fractures for both Specimen A and B are interface damage, matrix cracking, fiber/matrix debonding and fiber breakage in front and side view of the damaged composites. However, the damage regions and damage degrees are much more obvious in Specimen B as compared to Specimen A, and larger quantities of matrix cracking and fiber breakage occur in Specimen B. The cause of this phenomenon is that the additional axial yarns embedded amongst interlaced braiding yarns for 3D five directional braided composites, which helps Specimen B own much more yarns and have a more compact space structures than Specimen A. Besides, the ultimate breakage of a large number of axial and braiding yarns releases mass energy, thus resulting in relatively larger failure load and more obvious damage in 3D five directional braided composites $[47,48]$. According to the results observed by digital microscope, the damage characteristics from the physical mechanisms have been put forward. The real-time damage progress detection of 3D braided composite specimens will be analyzed according to the $A E$ and DIC methods, later.

\subsection{Characteristics of AE signals}

In this work, we selected two respective 3D braided composite specimens with different preform structures to study AE signal characteristics during the tensile testing. Figure 6 exhibits the AE amplitude and cumulative hits versus time for two types of specimens. Moreover, the corresponding $A E$ amplitude and stress versus strain for 3D braided composite specimens is shown in Fig. 7.

1. In the initial stage, firstly, no signal is detected and the stress is very low, which indicates that there is no damage and the specimens are in a completely elastic state. Then, a few AE signals with low amplitude (from 40 to $50 \mathrm{~dB}$ ) are obtained as the time and strain increases up to $10 \mathrm{~s}$ and $0.17 \%$ or so, respectively. Meanwhile, the cumulative hits and stress rise slowly, revealing the major damage modes of Specimen $A$ and $B$ are most probable internal manufacturing defects and interface micro-cracks of 3D braided composites under low load condition at this stage [49].

2. In the evolution stage, as stress increases, larger quantities of AE signals and cumulative hits are generated than the initial stage. This phenomenon shows that the damage degrees increase significantly. For Specimen A in Figs. $6 a$ and $7 a$, it can be found that the amplitude is mainly concentrated in $40-80 \mathrm{~dB}$, which suggests that the major damage modes like matrix cracking and fiber/matrix debonding may gradually occur [27]. Moreover, few high amplitude (from 80 to $100 \mathrm{~dB}$ ) $A E$ signals are generated, indicating the emergence of fiber breakage in Specimen A [50]. By contrast, the Specimen $B$ shown in Figs. $6 b$ and $7 b$ experiences $a$ similar phenomenon to Specimen $A$, and whereas much higher stress and much more $A E$ events appear in Specimen B during this stage. It is demonstrated that the damage arises much obviously in Specimen $B$.

3. In the failure stage, the number of AE signals and cumulative hits increases rapidly, which indicates the dramatic exacerbation of materials. Meanwhile, the total range of $A E$ amplitude is from 40 to $100 \mathrm{~dB}$ for (a) Specimen A(Three dimensional four directional)

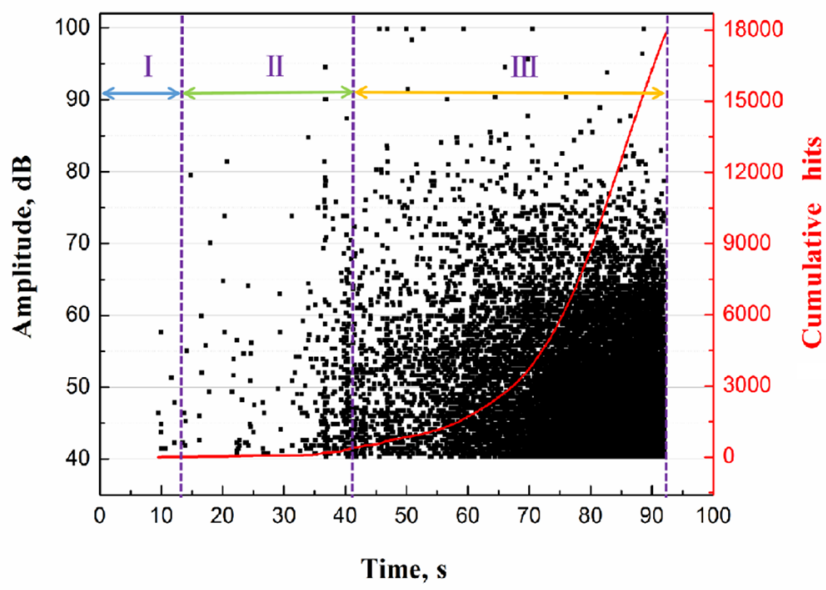

(b) Specimen B(Three dimensional five directional)

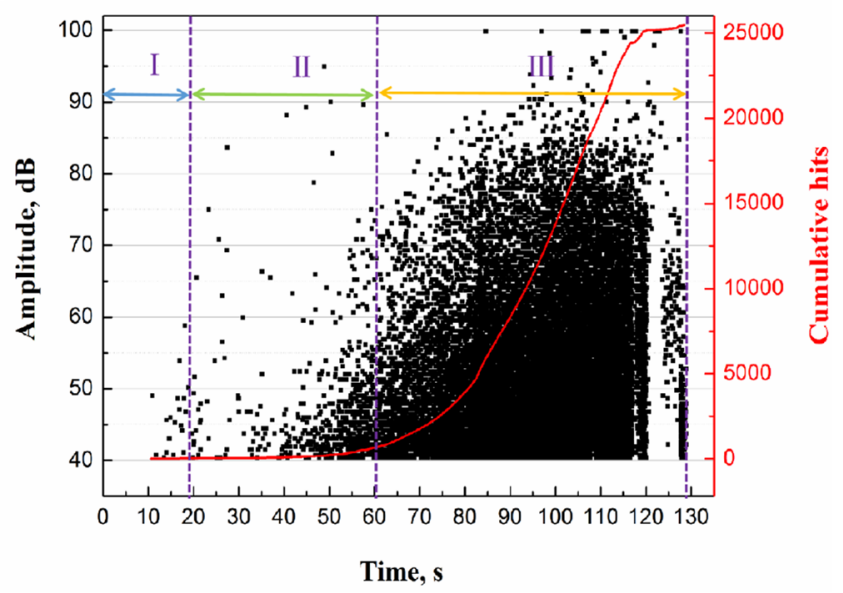

Fig. 6 The amplitude and cumulative hits versus time for 3D braided composite specimens 
(a) Specimen A(Three dimensional four directional)

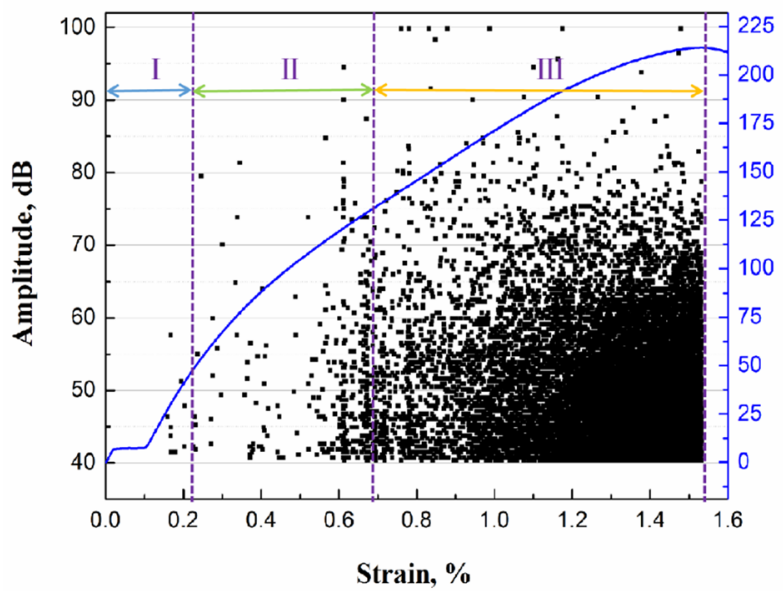

(b) Specimen B(Three dimensional five directional)

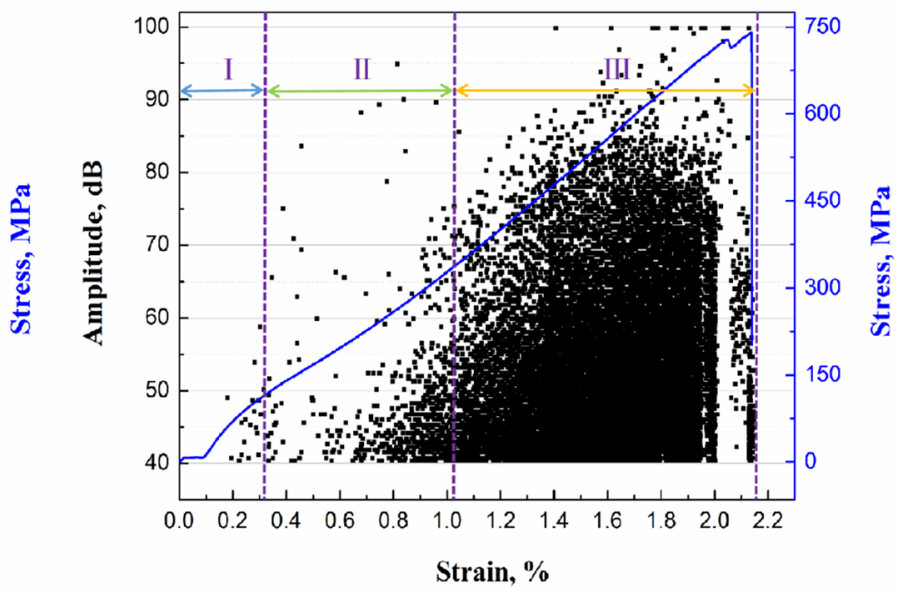

Fig. 7 The amplitude and stress versus strain for 3D braided composite specimens

Specimen $A$ and $B$, so the composites are accompanied by multiple damage modes like matrix cracking, fiber/matrix debonding and fiber breakage. Moreover, more high amplitude (from 80 to $100 \mathrm{~dB}$ ) AE signals are observed, indicating that the fiber damage is much severer in this stage. When the stress of Specimen A reaches maximum as shown in Fig. $7 \mathrm{a}$, the specimen fractures completely and releases a large amount of energy. Meanwhile, the cumulative hits of Specimen A reaches peak in Fig. $6 a$, as well. Besides, when the time and strain of Specimen B increase up to $120 \mathrm{~s}$ and $1.53 \%$ or so, the stress and the cumulative hits reach the first peak value indicating that the specimen approaches damage tolerance. Then, the stress curve has a slight drop and only high amplitude (from 80 to $100 \mathrm{~dB}) \mathrm{AE}$ signals are generated as depicted in Figs. 6 and 7b, which indicates that axial and braiding yarns cannot carry the heavy load, resulting in numerous fiber failure. Afterwards, the stress and cumulative hits reach maximum, the Specimen $B$ is completely broken. Comparing with the Specimen A in Figs. 6a and $7 \mathrm{a}$, more $A E$ signals with high amplitude and cumulative hits of Specimen B appear as illustrated in Figs. $6 \mathrm{~b}$ and $7 \mathrm{~b}$. This phenomenon further demonstrates that much more obvious damage is induced in Specimen B, which is in accord with the final damage morphology in Fig. 4. In order to further reflect the dynamic response behaviors of $A E$ signals, distinguish and quantify various types of irreversible damage and failure mechanisms, the AE statistical analysis method was studied in detail.

\subsection{Statistical analysis of AE signals}

The mechanical data and AE data of 3D braided composites are analyzed based on $\mathrm{C}++$ language. Meanwhile, the schematic diagram of damage state measurement and probability entropy calculation according to statistical analysis theory is shown in Fig. 8.

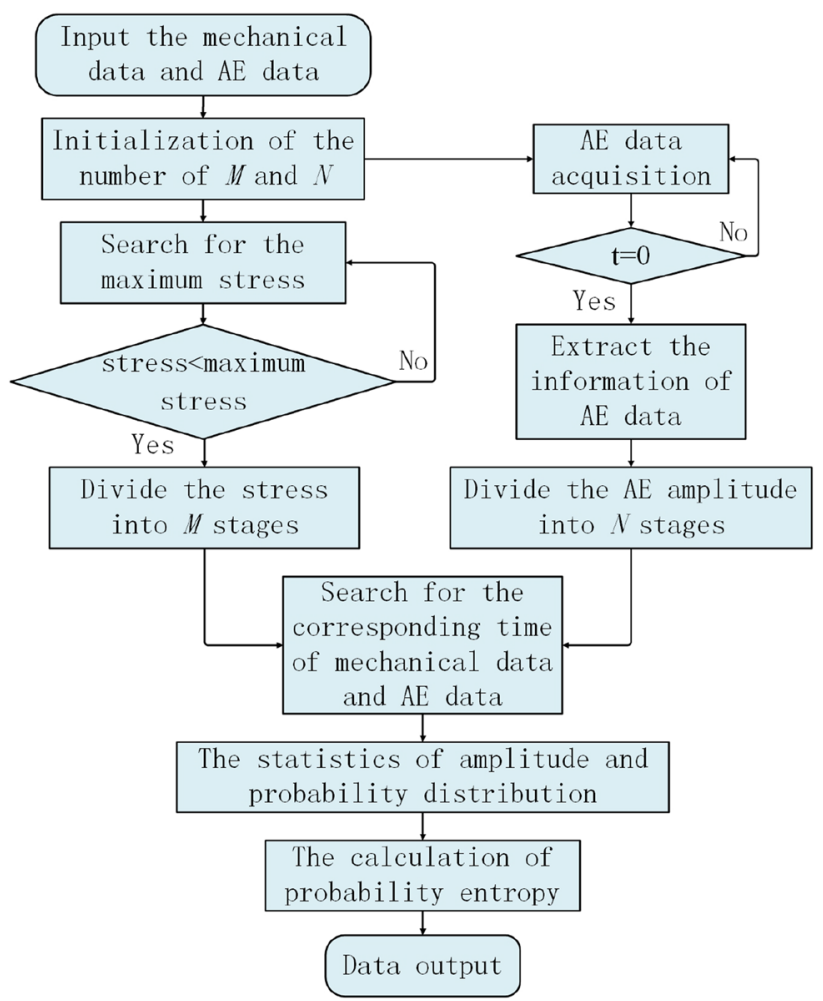

Fig. 8 The schematic diagram of statistical analysis method 
And the process of the statistical analysis method is as follow: Firstly, input the mechanical data and AE data of 3D braided composites. Besides, initialize the number of stress observation windows $M$ and $A E$ amplitude sub-intervals $N$. Secondly, search for the maximum stress and divide the stress into $M$ stages. Thirdly, extract the information of $A E$ data and divide the amplitude into $N$ equal sub-intervals. The next step is to combine stress levels with AE amplitude based on the corresponding time. Then, count the number of $A E$ events and probability in every amplitude sub-intervals at various stress levels. In the end, calculate the probability entropy of AE events and output data.

For 3D four directional and five directional braided composite specimens, there were no detectable $A E$ signals at or below $40 \mathrm{~dB}$ before the tensile tests, so the threshold of $A E$ system was set to $40 \mathrm{~dB}$. Meanwhile, the maximum amplitude of Specimen $A$ and $B$ during the tests were approach to $100 \mathrm{~dB}$. Therefore, the measured amplitude range of acquired RME for Specimen $A$ and $B$ were in the interval from 40 to $100 \mathrm{~dB}$. In this work, we use $N=6$, so the interval is divided into six equal sub-intervals, and each of them is from $40+10(j-1)$ to $40+10 j \mathrm{~dB}(j=1, \ldots, 6)$, and the RME amplitude bandwidth are $10 \mathrm{~dB}$. The amplitude spectrum at various stress levels for typical 3D braided composite specimens is shown in Fig. 9. Each individual spectrum quantifies a damage state at corresponding applied stress levels, and the mode of every amplitude spectrum is one of the important factors of the association between RME occurred at various stress levels.

It is found that $A E$ events with low amplitude are dominant in initial stage and the main damage is small scale micro-damage of 3D braided composites. As the applied stress increases, AE events with higher amplitude continuously occur and gradually form bigger bandwidth of

(a) Specimen $\mathrm{A}$ (Three dimensional four directional)

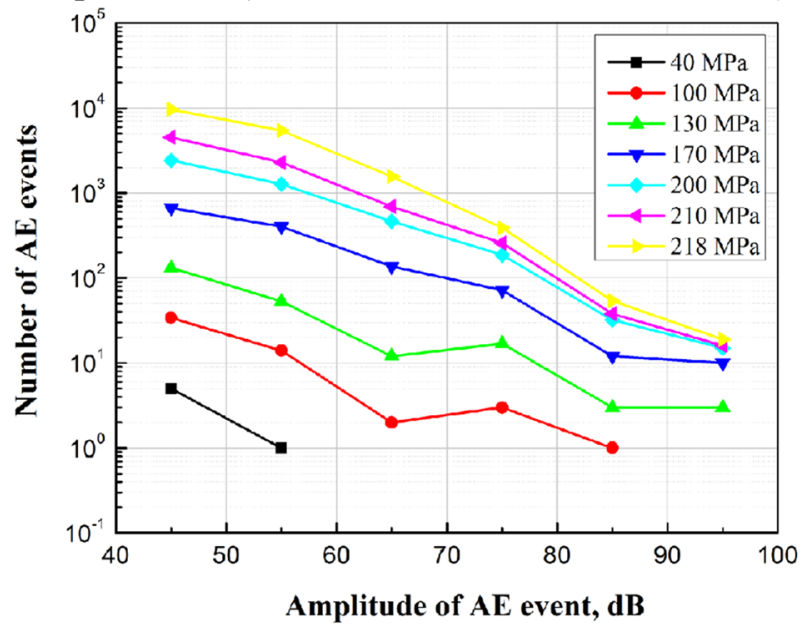

amplitude spectrum, which corresponds to the increasing occurrence of damage. When the applied stress increases up to $100 \mathrm{MPa}$ for Specimen A and $200 \mathrm{MPa}$ for Specimen $B$, the amplitude spectrum ranges from 40 to $90 \mathrm{~dB}$. While the stress is $130 \mathrm{MPa}$ for Specimen A and $340 \mathrm{MPa}$ for Specimen $B$, the amplitude spectrum ranges from 40 to $100 \mathrm{~dB}$. Meanwhile, the $A E$ events emerge in the highest amplitude sub-interval, and the entire bandwidths of amplitude spectrum are gradually formed. This transitional zones appear between 100 and $130 \mathrm{MPa}$ for Specimen A, and between 200 and $340 \mathrm{MPa}$ for Specimen B. Then, we can see an altered shape of $A E$ amplitude distribution, which indicates numerous new damage modes arise. Afterward, $A E$ events with larger amplitude increase, indicating more RME occur in the highest amplitude sub-interval. Furthermore, from the general tendency of amplitude spectrum, the number of $A E$ signals with low amplitude is more than that with high amplitude. Besides, as the increase of amplitude in every observation window at corresponding stress levels, the number of AE events decrease obviously. The tendency agrees well with that in Figs. 6 and 7. Once the stress approaches to maximum, the quantities of $A E$ events increase apparently, but the amplitude spectrum has no obvious change in shape. This phenomenon indicates that the degree of damage increases significantly, while no new damage mode is induced. The distribution of amplitude spectrum in Fig. 9b is similar to that in Fig. 9a, but the total quantities of $A E$ events in Specimen $A$ are lower than that in Specimen B. This can be attributed to more obvious damage of 3D five directional braided composites, which is associated with the final damage morphology in Fig. 4.

Figure 10 exhibits the approximated Gibbs probability distribution of $A E$ events at various stress levels for the typical 3D braided composite specimens. It is demonstrated

(b) Specimen B(Three dimensional five directional)

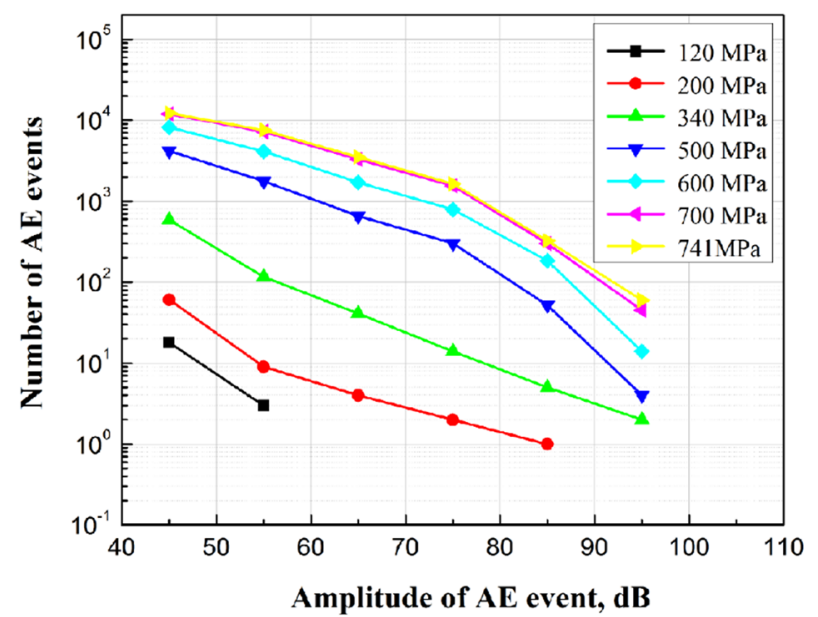

Fig. 9 The amplitude spectrum at various stress levels for 3D braided composite specimens 
(a) Specimen A(Three dimensional four directional)

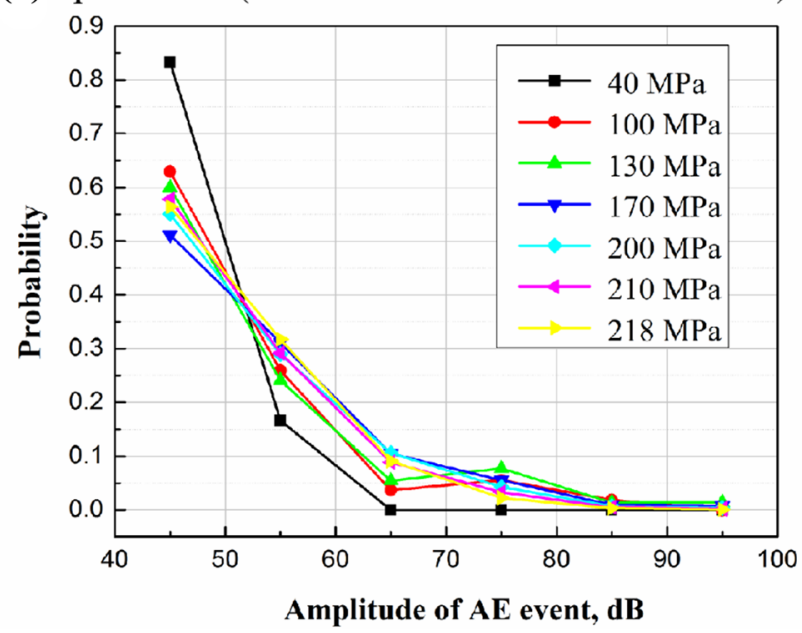

(b) Specimen B(Three dimensional five directional)

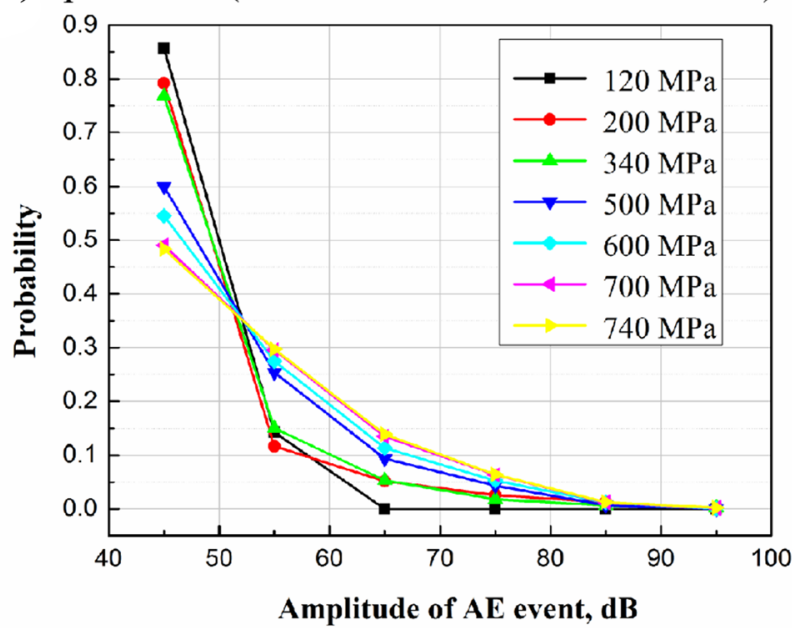

Fig. 10 The approximated Gibbs probability distribution of AE events at various stress levels for 3D braided composite specimens

that the probability of RME with low amplitude is obviously bigger than those of high amplitude, only an exception in Fig. 10a, which agrees well with the distribution of amplitude spectrum in Fig. 9. The phenomenon shows that the damage corresponding to the AE events with lower amplitude is continued occurrence during the whole tensile process and the damage modes in the initial stage have more uncertainty. Once the whole spectral region is formed, for each selected stress levels, the probability distribution is in the form of an exponential function [51], it is inferred that the uncertainty of damage has a slight decrease. As the applied stress is near to the breaking point, the probability distribution is almost unchanged, revealing the damage develops in a certain direction. Thus,

(a) Specimen $\mathrm{A}$ (Three dimensional four directional)

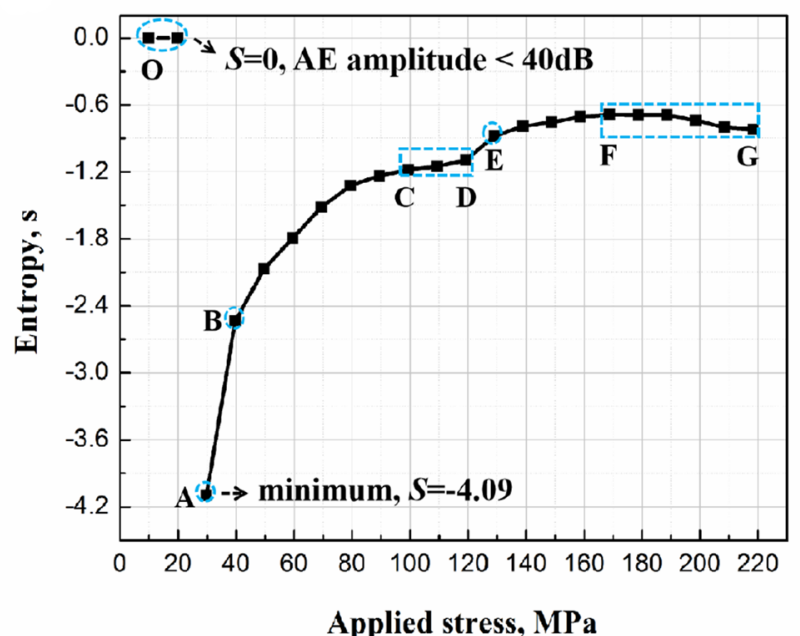

the normalized Gibbs probability distribution can further describe damage state of RME.

Figure 11 presents the probability entropy of AE events at various stress levels for 3D braided composite specimens. To increase the accuracy of the calculated entropy, the number of equal sub-intervals of amplitude is set to 60 . So, the total bandwidth of the amplitude spectrum for Specimen $A$ and $B$ are $60 \mathrm{~dB}$. Besides, the number of the observation window of stress in Fig. 11a, b is set to 22 and 37 , respectively. Hence, for Specimen $\mathrm{A}, M=22, N=60$, the entropy is observed every $10 \mathrm{MPa}$, while Specimen $B$ is observed every $20 \mathrm{MPa}$, and $M=37, N=60$. Overall, the damage process can be split into the following three stages:

(b) Specimen B(Three dimensional five directional)

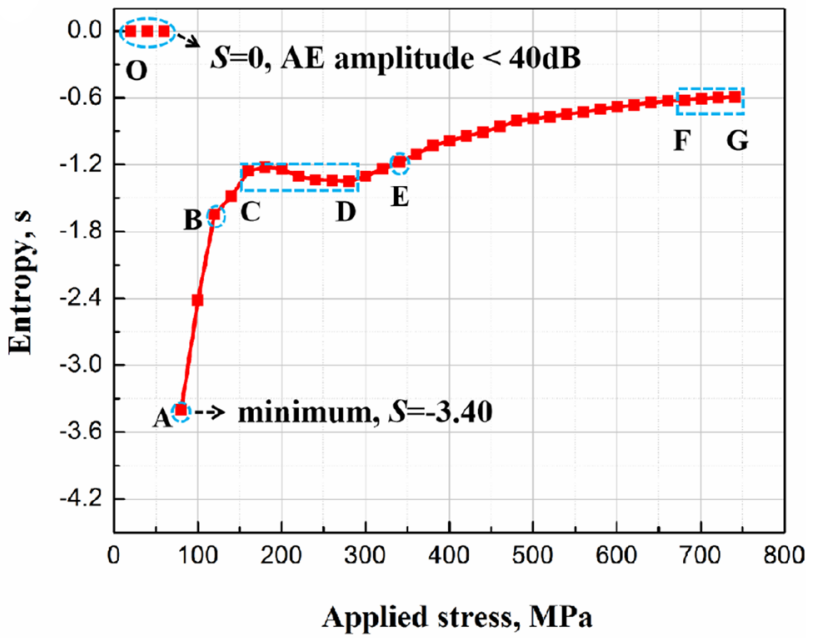

Fig. 11 The probability entropy of AE events at various stress levels for 3D braided composite specimens 
1. At the initial damage stage (from $O$ to $B$ ), firstly, there is no $A E$ events with amplitude over $40 \mathrm{~dB}$, the entropy of Specimen $A$ and $B$ is 0 . As we can see, when stress increases up to $30 \mathrm{MPa}$ (point $A$ in Fig. 11a), all acquired RME fall in the same scale sub-interval, the entropy of Specimen $A$ reaches the minimum, $S=-4.09$. Similarly, at around $80 \mathrm{MPa}$ (point $\mathrm{A}$ in Fig. 11b), the least entropy of Specimen $B$ appears, that is about $S=-3.40$. Then, the entropy begins to increase linearly (from $A$ to $\mathrm{B}, d s / d \sigma \approx$ constant $>0$ ), which corresponds to the existence of $A E$ events with higher amplitude and some uncertain small-scale damage in internal and interface of 3D braided composites under low loading condition.

2. At the damage evolution stage (from $B$ to $E$ ), as the stress increases, the growth rate of entropy has gradually decreases (from B to $C, d s / d \sigma>0, d^{2} s / d \sigma^{2}<0$ ), revealing the appearance of new damage modes and a slight drop of uncertain damage may be accompany by matrix cracking and fiber/matrix debonding of 3D braided composites. When the stress increases from 100 to $120 \mathrm{MPa}$ (from C to $D$ in Fig. 11a), the slope of Specimen $\mathrm{A}$ is approximately $0(d s / d \sigma \approx 0)$. Meanwhile, as the stress increases from 160 to $280 \mathrm{MPa}$, (from C to D in Fig. 11b), the entropy of Specimen B is approximately constant or with a slight downward $(d s / d \sigma \leq 0)$. The results indicate that the responses of inherent microscopic structure under the applied stress are nearly identical and no new damage modes arise. Afterwards, the entropy has a linear increase (from $\mathrm{D}$ to $\mathrm{E}, d s / d \sigma \approx$ constant $>0$ ), then the detected $A E$ events start to emerge in all 60 sub-intervals, resulting in the formation of the entire spectrum bandwidth (point $\mathrm{E}$ ). This transition is related to the change in shape of the curves as shown in Fig. 9, the amplitude distribution includes an apparently larger occurrence of high amplitude signals, indicating that besides matrix cracking and fiber/matrix debonding, a small amount of fiber breakage occurs at this stage as well.

3. At the failure stage (from $E$ to $G$ ), the entropy significantly increases ( $d s / d \sigma>0)$, which is consistent with the increasing number of RME, meaning the uncertainty of damage state increases rapidly and multiple damage modes occur during this stage. Meanwhile, the more and more severe damage like fiber failure starts to emerge and evolve. When the stress approximates to peak value, the entropy increases up to maximum and the variation of entropy remains unchanged or minimum (from $\mathrm{F}$ to $\mathrm{G}$ ), meaning the damage state maintains almost constant and the number of RME grow evidently in few certain scales. Compared to Specimen A, the entropy of Specimen B is a little larger at this damage stage. The phenomenon further indicates that the final damage is much more obvious in 3D five directional braided composites, which is associated with the mechanical and damage characteristics of 3D braided composites.

Therefore, the use of probability entropy can well reveal the state and evolution of the randomly generated damage modes during the tensile tests. The statistical analysis of $A E$ signals with amplitude spectrum, normalized probability distribution and probability entropy can be used as criterion quantitatively to distinguish and quantify various types of irreversible damage and failure mechanisms in 3D braided composites.

\subsection{Distribution of strain fields}

The two dimensional DIC method was adopted for measuring the full-field strain distribution at surface of the investigated 3D braided composite specimens by searching for the maximum correlation coefficient $C$ between the reference images $f$ and deformed images $g$. Moreover, the correlation coefficient $C(u, v)$ can be expressed by Eq. (9):

$$
C(u, v)=\frac{\sum_{i=1}^{m} \sum_{j=1}^{m}\left[f\left(x_{i}, y_{j}\right)-\bar{f}\right]\left[g\left(x_{i}^{\prime}, y_{j}^{\prime}\right)-\bar{g}\right]}{\sqrt{\sum_{i=1}^{m} \sum_{j=1}^{m}\left[f\left(x_{i}, y_{j}\right)-\bar{f}\right]^{2}} \sqrt{\sum_{i=1}^{m} \sum_{j=1}^{m}\left[g\left(x_{i}^{\prime}, y_{j}^{\prime}\right)-\bar{g}\right]^{2}}}
$$

Here, $f(x, y)$ is the gray value of the reference image and $g\left(x^{\prime}, y^{\prime}\right)$ is the gray value of the deformed image. $\bar{f}$ and $\bar{g}$ are the average gray value of $f(x, y)$ and $g\left(x^{\prime}, y^{\prime}\right)$, respectively. During the tensile tests, the strain in the vertical direction $\varepsilon_{y}$ at different stress levels was calculated exactly by the DIC processing software, which is based on the gray scale distribution of digital images [50-52].

Figures 12 and 13 show the front view of vertical strain distribution for Specimen $A$ and $B$ at specific stress levels, respectively. As illustrated in Fig. 12, when the stress increases from 70 to $80 \mathrm{MPa}, 130$ to $140 \mathrm{MPa}$ and 170 to $180 \mathrm{MPa}$, the maximum strain in vertical direction of Specimen $A$ is $0.010000,0.012500$ and $0.017000 \varepsilon$, respectively. Meanwhile, the corresponding average strain is 0.000438 , 0.000496 and $0.000754 \varepsilon$. For Specimen B, an obvious change can be observed from Fig. 13a-c. As the stress increases from 170 to $180 \mathrm{MPa}, 530$ to $540 \mathrm{MPa}$ and 690 to $700 \mathrm{MPa}$, the maximum vertical strain value is 0.002760 , 0.004220 and $0.024200 \varepsilon$, respectively. Correspondingly, the average strain is $0.000134,0.000276$ and $0.000353 \varepsilon$, as summarized in Table 3.

Furthermore, Figs. 14 and 15 exhibit the side view of vertical strain distribution for Specimen $A$ and $B$ at specific stress levels, respectively. As shown in Fig. 14, when 

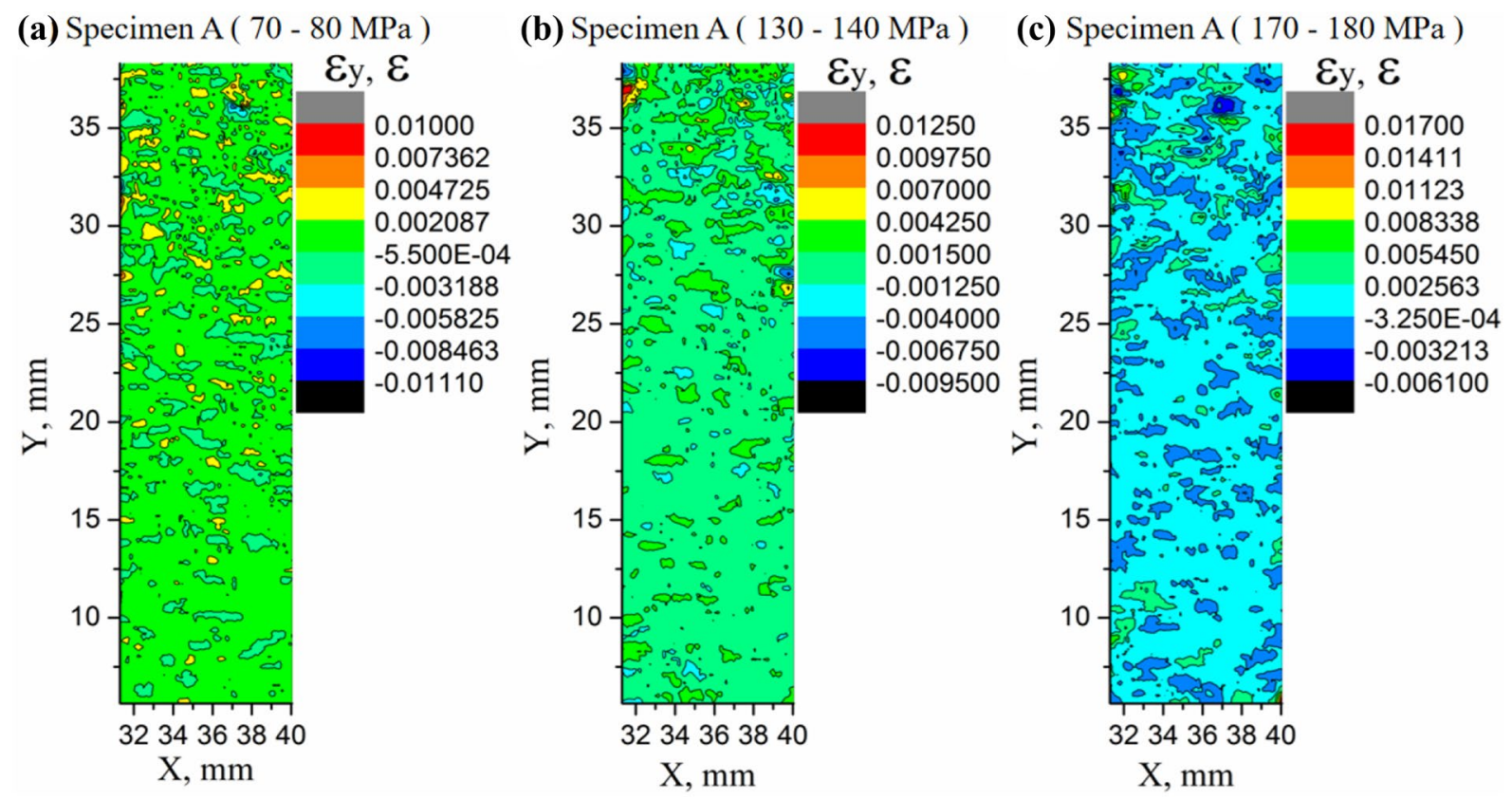

Fig. 12 The front view of vertical strain distribution for Specimen A at specific stress levels a $70-80 \mathrm{MPa}$, b $130-140 \mathrm{MPa}$ and c $170-180 \mathrm{MPa}$, respectively
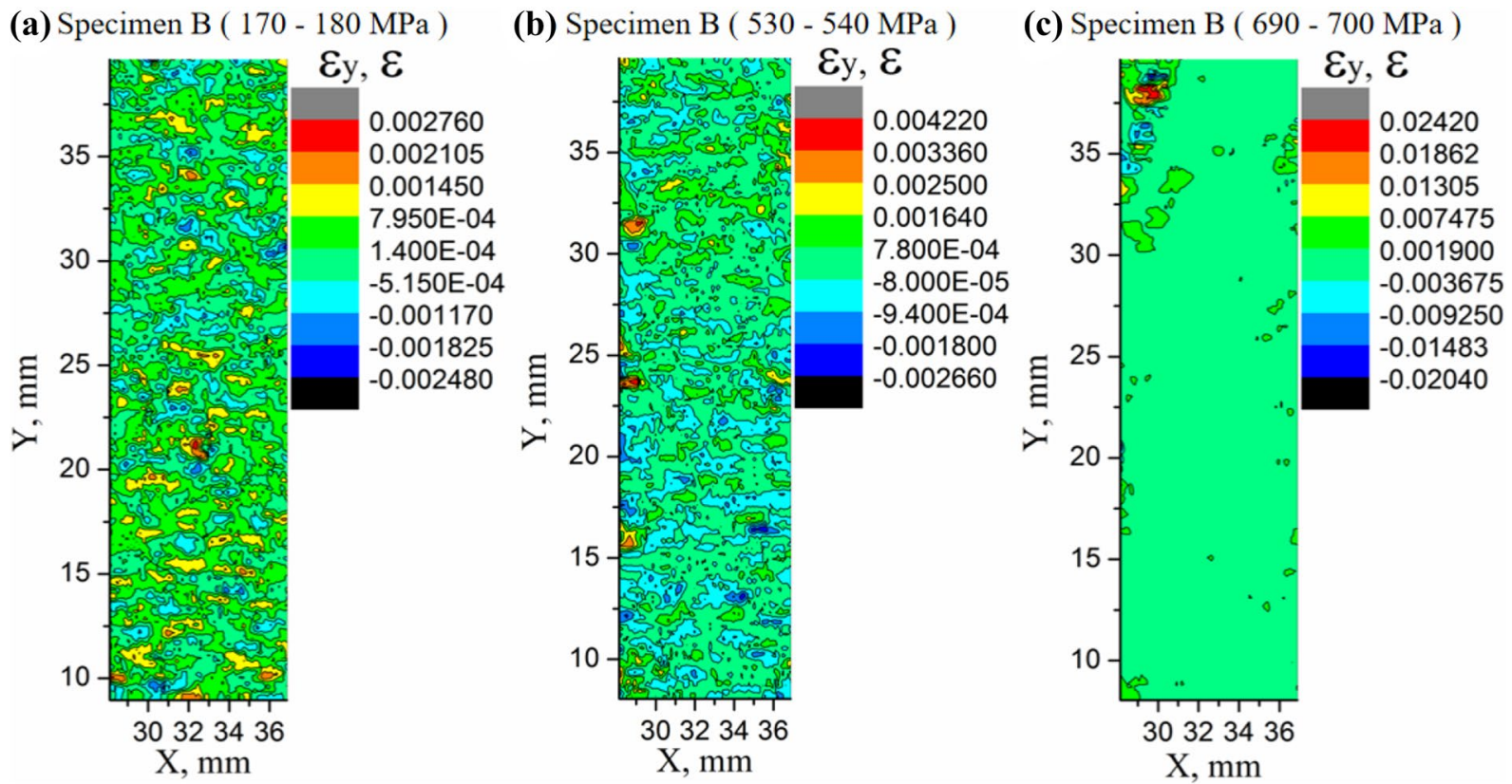

Fig. 13 The front view of vertical strain distribution for Specimen B at specific stress levels a $170-180 \mathrm{MPa}$, b $530-540 \mathrm{MPa}$ and c $690-$ $700 \mathrm{MPa}$, respectively

Table 3 The vertical strain values (front) for Specimen $A$ and $B$ at different stress levels

\begin{tabular}{llllllll}
\hline Front & \multicolumn{3}{l}{ Specimen $\mathrm{A}$} & & \multicolumn{3}{l}{ Specimen $\mathrm{B}$} \\
\cline { 2 - 4 } Vertical & $70-80 \mathrm{MPa}$ & $130-140 \mathrm{MPa}$ & $170-180 \mathrm{MPa}$ & & $170-180 \mathrm{MPa}$ & $530-540 \mathrm{MPa}$ & $690-700 \mathrm{MPa}$ \\
\hline $\max \varepsilon_{y}, \varepsilon$ & 0.010000 & 0.012500 & 0.017000 & & 0.002760 & 0.004220 & 0.024200 \\
$\overline{\varepsilon_{y}}, \varepsilon$ & 0.000438 & 0.000496 & 0.000754 & & 0.000134 & 0.000276 & 0.000353 \\
\hline
\end{tabular}


(a) Specimen A ( 70 - $80 \mathrm{MPa})$ (b)

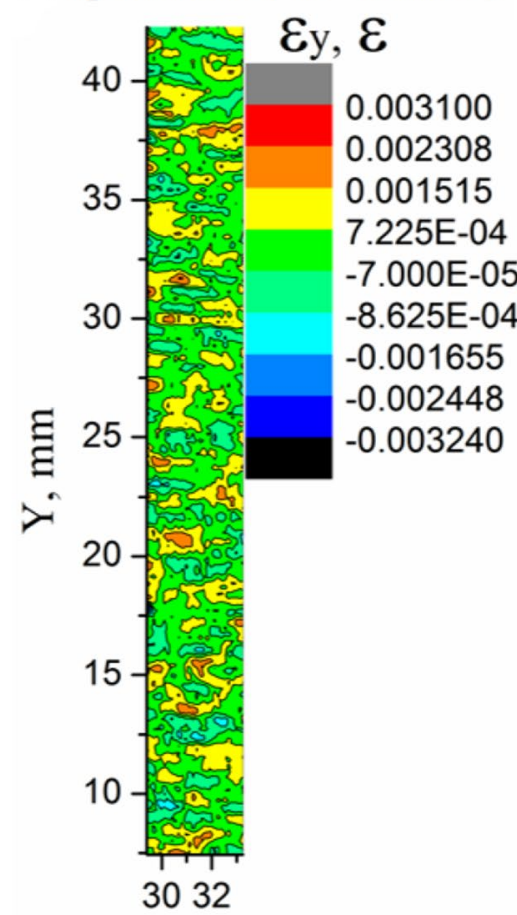

$\mathrm{X}, \mathrm{mm}$ (b) Specimen A ( 130 - $140 \mathrm{MPa}$ ) (c) Specimen A ( 170 - $180 \mathrm{MPa}$ )

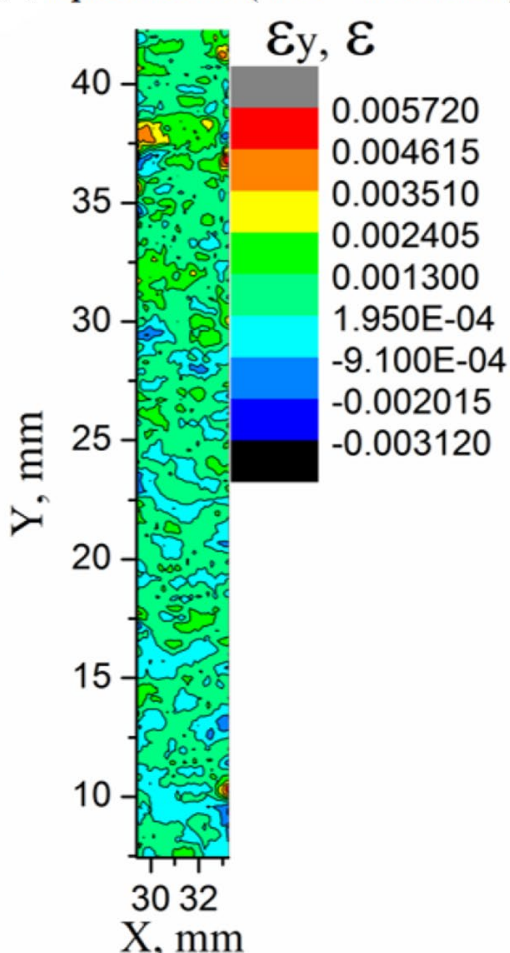

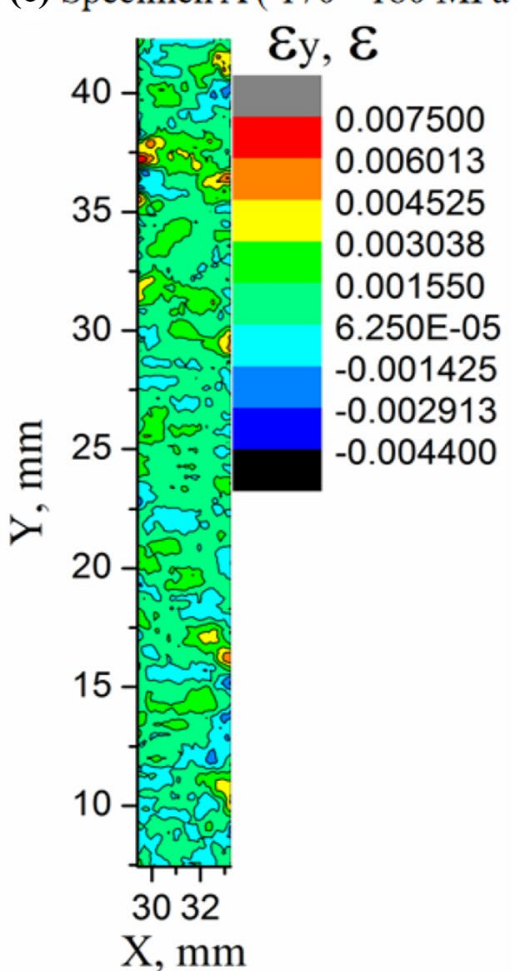

Fig. 14 The side view of vertical strain distribution for Specimen A at specific stress levels a 70-80 MPa, b 130-140 MPa and c $170-180$ MPa, respectively

the stress of Specimen A increases from 70 to $80 \mathrm{MPa}, 130$ to $140 \mathrm{MPa}$ and 170 to $180 \mathrm{MPa}$, the maximum vertical strain is $0.003100,0.005720$ and $0.007500 \varepsilon$, respectively. Meanwhile, the corresponding average strain is 0.000444 , 0.000649 and $0.000850 \varepsilon$. From Fig. 14a-c, when the stress increases from 170 to $180 \mathrm{MPa}, 530$ to $540 \mathrm{MPa}$ and 690 to $700 \mathrm{MPa}$, the maximum strain value of Specimen $\mathrm{B}$ is $0.004800,0.012800$ and $0.066500 \varepsilon$, respectively. Correspondingly, the average strain is $0.000144,0.000155$ and $0.000516 \varepsilon$, as listed in Table 4 .

According to the strain analysis results, it can be found that the vertical strain value in the front and side direction of Specimen A and B become larger, as the stress increases at same increment. Furthermore, the number of AE signals also increases gradually as illustrated in Figs. 6 and 7. When the stress increases from 70 to $80 \mathrm{MPa}$ for Specimen $A$ and 170 to $180 \mathrm{MPa}$ for Specimen B, it can be seen that the range of $A E$ amplitude and the rate of $A E$ cumulative hits are relatively low. As the stress increases from 130 to $140 \mathrm{MPa}$ for Specimen A and 530 to $540 \mathrm{MPa}$ for Specimen $B$, the $A E$ events emerge in every amplitude range and there is a slight increase of the rate of $A E$ cumulative hits. And at the last stage from 170 to $180 \mathrm{MPa}$ for Specimen $A$ and 690 to $700 \mathrm{MPa}$ for Specimen B, larger quantities of $A E$ signals emerge and the rate of $A E$ cumulative hits increases significantly. The remarkable increase of strain in loading direction and the number of typical AE characteristic parameters indicates that the yarns and matrix are increasingly damaged, leading to the reduction of carrying capacity of composites. By contrast, the average strain level of Specimen B is a little lower than that of Specimen A at the same stage of tensile testing, further indicating that the more compact fiber perform architectures in Specimen $B$ increases the deformation resistibility capacity of 3D five directional braided composites [53, 54].

Moreover, it is clearly observed that the distribution of strain fields for both Specimen A and B are all inhomogeneity and scattered in blocks of irregular shape, which further proves the structural complexity and mechanical anisotropy of 3D braided composite $[55,56]$. Once the applied stress approaches to maximum as shown in Figs. 12c-14c, the strain in vertical direction grow substantially. Meanwhile, as we can see from Figs. 6 and 7, the corresponding $A E$ signals are adequate at this critical moment and some high amplitude signals are generated and $A E$ cumulative hits increase rapidly, as well. Besides, the maximum failure-to-strain of Specimen $B$ is much higher than that of Specimen A. It also demonstrates the peak stress and tensile strength are higher in Specimen B. In addition, an obvious local strain concentration in loading direction 
(a) Specimen B ( $170-180 \mathrm{MPa})(\mathrm{b})$
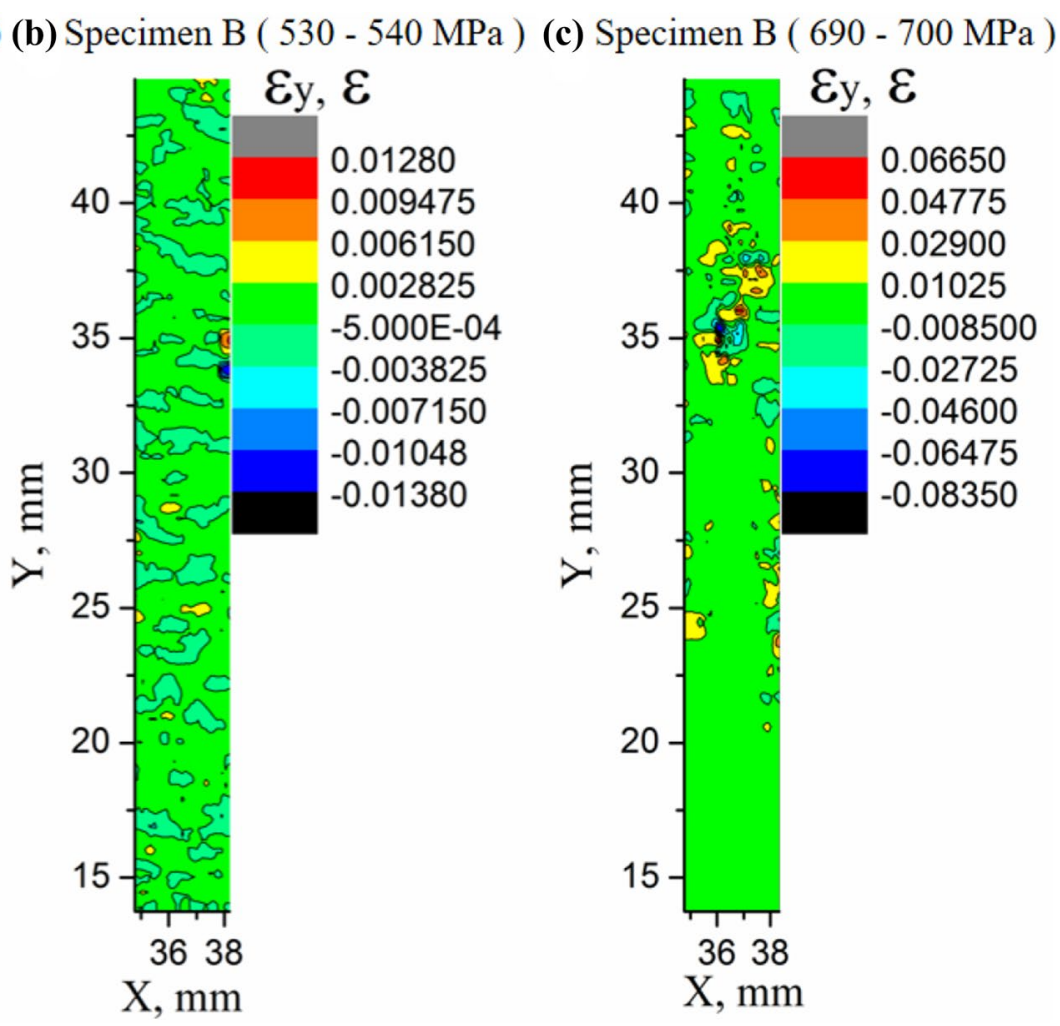

Fig. 15 The side view of vertical strain distribution for Specimen B at specific stress levels a 170-180 MPa, b 530-540 MPa and c 690$700 \mathrm{MPa}$, respectively

Table 4 The vertical strain values (side) for Specimen $A$ and $B$ at different stress levels

\begin{tabular}{llllllll}
\hline Side & \multicolumn{2}{l}{ Specimen $\mathrm{A}$} & & & \multicolumn{3}{l}{ Specimen $\mathrm{B}$} \\
\cline { 2 - 4 } Vertical & $70-80 \mathrm{MPa}$ & $130-140 \mathrm{MPa}$ & $170-180 \mathrm{MPa}$ & & $170-180 \mathrm{MPa}$ & $530-540 \mathrm{MPa}$ & $690-700 \mathrm{MPa}$ \\
\hline $\max \varepsilon_{y^{\prime}} \varepsilon$ & 0.003100 & 0.005720 & 0.007500 & & 0.004800 & 0.012800 & 0.066500 \\
$\overline{\varepsilon_{y}, \varepsilon}$ & 0.000444 & 0.000649 & 0.000850 & & 0.000144 & 0.000155 & 0.000516 \\
\hline
\end{tabular}

of Specimen B can be observed in Figs. $13 \mathrm{c}$ and $15 \mathrm{c}$, reveling more obvious final damage in 3D five directional braided composites.

To sum up, the diversification of side strain distribution is consistent with that of front strain distribution. And the analysis results measured by DIC method are associated well with the characteristics of $A E$ signals discussed in precious. Therefore, the variation of strain fields measured the deformation at surface of the specimens and AE technology describes the damage evolution of 3D braided composites, providing failure criterion for braided composites.

\section{Conclusions}

In summary, numerous tensile tests were carried out for simultaneously monitoring the mechanical behaviors and damage properties of 3D four directional and five directional braided composites based on $\mathrm{AE}$ and DIC analysis methods. It can be found that the more compact perform structure with additional axial reinforced yarns of 3D five directional braided composites increases longitudinal load-bearing and deformation resistibility capacity. Besides, both two kinds of 3D braided composites exhibit graceful failure, while the damage modes like interface damage, matrix cracking, fiber/matrix debonding and fiber breakage are much more obvious in 3D five directional braided composites, due to huge energy release from the ultimate breakage of a large number of axial and braiding yarns. Furthermore, the AE signals collected during tensile process were post processed by statistical analysis method in detail. According to the amplitude spectrum, normalized probability distribution and probability entropy, the evolving irreversible damage state of 3D braided composites during tensile tests were recognized and assessed successfully. Therefore, by the use of statistical analysis 
method, the failure criterion of braided composites can be established and developed effectively. Meanwhile, the deformation and damage evolution of specimens are further monitored by AE and DIC methods, which provides damage and failure criterion for two types of composites. As for the future studies, the effect of other important factors such as braiding angles or other braiding parameters, temperature, and the free-edge effect of specimen will be investigated to further reveal the mechanical and damage behaviors of $3 \mathrm{D}$ braided composites.

Acknowledgements The authors of this paper wish to acknowledge the financial support of the National Natural Science Foundation of China (Grant Nos. 11502064 and 11572109).

\section{Compliance with ethical standards}

Conflict of interest The author(s) declared no potential conflicts of interest with respect to the research, authorship, and/or publication of this article.

\section{References}

1. Sun J, Wang Y, Zhou GM et al (2018) Finite element analysis of mechanical properties of 3D surface-core braided composites. Polym Compos 39(4):1076-1088

2. Fan W, Li JL, Chen L et al (2016) Influence of thermo-oxidative aging on vibration damping characteristics of conventional and graphene-based carbon fiber fabric composites. Polym Compos 37(9):2871-2883

3. Zhang C, Curiel-Sosa JL, Tinh QB (2019) Meso-scale finite element analysis of mechanical behavior of 3D braided composites subjected to biaxial tension loadings. Appl Compos Mater 26(1):139-157

4. Zhang C, Curiel-Sosa JL, Bui TQ (2017) A novel interface constitutive model for prediction of stiffness and strength in 3D braided composites. Compos Struct 163:32-43

5. Zhang C, Curiel-Sosa JL, Duodu EA (2017) Finite element analysis of the damage mechanism of 3D braided composites under high-velocity impact. J Mater Sci 52(8):4658-4674

6. Yan S, Guo LY, Zhan JY et al (2017) Effect of braiding angle on the impact and post-impact behavior of 3D braided composite. Strength Mater 49(1):198-205

7. Zhai JJ, Cheng S, Zeng T et al (2017) Thermo-mechanical behavior analysis of 3D braided composites by multiscale finite element method. Compos Struct 176:664-672

8. Li XK, Liu ZG, Hu L et al (2017) Numerical investigation of T-joints with 3D four directional braided composite fillers under tensile loading. Appl Compos Mater 24(1):171-191

9. Liu XY, Ma YJ, Yao XF (2013) Experimental investigation of deformation and fracture in multilayered graded material. J Strain Anal Eng Des 48(8):474-481

10. Felipe-Sesé L, Siegmann P, Díaz FA et al (2014) Simultaneous inand-out-of-plane displacement measurements using fringe projection and digital image correlation. Opt Lasers Eng 52:66-74

11. Felipe-Sesé L, Diaz-Garrido FA, Patterson EA (2016) Exploiting measurement-based validation for a high-fidelity model of dynamic indentation of a hyperelastic material. Int J Solids Struct 97-98:520-529
12. Felipe-Sesé L, Díaz FA (2018) Damage methodology approach on a composite panel based on a combination of fringe projection and 2D digital image correlation. Mech Syst Signal Process 101:467-479

13. Feissel P, Schneider J, Aboura Z et al (2013) Use of diffuse approximation on DIC for early damage detection in $3 \mathrm{D}$ carbon/epoxy composites. Compos Sci Technol 88:16-25

14. Zheng YY, Sun Y, Li JL et al (2017) Tensile response of carbonaramid hybrid 3D braided composites. Mater Des 116:246-252

15. Momon S, Moevus M, Godin N et al (2010) Acoustic emission and lifetime prediction during static fatigue tests on ceramicmatrix-composite at high temperature under air. Compos Part A Appl Sci Manuf 41(7):913-918

16. Wang X, Zhang HP, Yan X (2011) Classification and identification of damage mechanisms in polyethylene self-reinforced laminates by acoustic emission technique. Polym Compos 32(6):945-959

17. Goutianos S (2019) Acoustic emission characteristics of unidirectional glass/epoxy composites under mixed-mode fracture. SN Appl Sci 1(5):474

18. Su H, Zhang TY, Zhang N (2016) Acoustic emission based defects monitoring of three-dimensional braided composites using wavelet network. Int J Smart Sens Intell Syst $9(2): 780-798$

19. Nag-Chowdhury S, Bellegou H, Pillin I et al (2018) Crossed investigation of damage in composites with embedded quantum resistive strain sensors (SQRS), acoustic emission (AE) and digital image correlation (DIC). Compos Sci Technol 160:79-85

20. Liakat M, Khonsari MM (2014) Rapid estimation of fatigue entropy and toughness in metals. Mater Des 62:149-157

21. Romhány G, Czigány T, Karger-Kocsisa J (2017) Failure assessment and evaluation of damage development and crack growth in polymer composites via localization of acoustic emission events: a review. Polym Rev 57(3):397-439

22. De-Jager D, Zweiri Y, Makris D (2019) A particle swarm optimization approach using adaptive entropy-based fitness quantification of expert knowledge for high-level, real-time cognitive robotic control. SN Appl Sci 1(12):1684

23. Momon S, Godin N, Reynaud P et al (2012) Unsupervised and supervised classification of $A E$ data collected during fatigue test on CMC at high temperature. Compos Part A Appl Sci Manuf 43(2):254-260

24. Liakat $M$, Khonsari MM (2015) On the anelasticity and fatigue fracture entropy in high-cycle metal fatigue. Mater Des 82:18-27

25. Tanvir F, Sattar T, Mba D et al (2020) Identification of fatigue damage evaluation using entropy of acoustic emission waveform. SN Appl Sci 2(1):138

26. Qi G, Wayne SF, Penrose O et al (2010) Probabilistic characteristics of random damage events and their quantification in acrylic bone cement. J Mater Sci Mater Med 21(11):2915-2922

27. Zhou W, Lv ZH, Wang YR et al (2015) Acoustic response and micro-damage mechanism of fiber composite materials under mode-II delamination. Chin Phys Lett 32(4):77-80

28. Kahirdeh A, Khonsari MM (2016) Acoustic entropy of the materials in the course of degradation. Entropy 18(8):280

29. ASTM D638/D638-14 (2014) Standard test method for tensile properties of plastics. ASTM International, West Conshohocken

30. Zhang DT, Chen L, Sun Y et al (2016) Meso-scale progressive damage of 3D five-directional braided composites under transverse compression. J Compos Mater 50(24):3345-3361

31. Zhang C, Binienda WK, Goldberg RK (2015) Free-edge effect on the effective stiffness of single-layer triaxially braided composite. Compos Sci Technol 107:145-153

32. ASTM D3039/D3039M-14 (2014) Standard test method for tensile properties of polymer matrix composite materials. ASTM International, West Conshohocken 
33. GB/T 33613-2017 (2017) Test method for tensile properties of $3 \mathrm{D}$ braided fabric and its polymer matrix composites. National Standard of the People's Republic of China, Taiwan

34. Rosti J, Koivisto J, Alava MJ (2010) Statistics of acoustic emission in paper fracture: precursors and criticality. J Stat Mech Theory Exp 2010:P02016

35. Qi G, Wayne S, Mann K et al (2010) Random damage and characteristics of debris particles are two important and yet ignored factors in the mechanical integrity of the stem-cement interface of a total hip replacement: influence of the surface finish of the metal stem. J Mater Sci Mater Med 21:1385-1392

36. Qi G, Li JY, Fan M et al (2013) Assessment of statistical responses of multi-scale damage events in an acrylic polymeric composite to the applied stress. Probab Eng Mech 33:103-115

37. Mehdizadeh M, Khonsari MM (2018) On the application of fracture fatigue entropy to variable frequency and loading amplitude. Theor Appl Fract Mech 98:30-37

38. Sung-Choong W, Tae-Won K (2016) High strain-rate failure in carbon/kevlar hybrid woven composites via a novel SHPB-AE coupled test. Compos Part B Eng 97:317-328

39. Loutas T, Eleftheroglou N, Zarouchas D (2017) A data-driven probabilistic framework towards the in situ prognostics of fatigue life of composites based on acoustic emission data. Compos Struct 161:522-529

40. Qi G, Fan M, Lewis G et al (2012) An innovative multi-component variate that reveals hierarchy and evolution of structural damage in a solid: application to acrylic bone cement. J Mater Sci Mater Med 23(2):217-228

41. Qi G, Wayne SF, Fan M (2011) Measurements of a multicomponent variate in assessing evolving damage states in a polymeric material. IEEE Trans Instrum Meas 60(1):206-213

42. Zhang L, Fan M, Li JY (2015) Statistical analysis of events of random damage in assessing fracture process in paper sheets under tensile load. Adv Acoust Emiss Technol 158:267-281

43. Liu Y, Chen ZF, Zhu JX et al (2012) Comparison of 3D four-directional and five-directional braided $\mathrm{SiO}_{2 f} / \mathrm{SiO}_{2}$ composites with respect to mechanical properties and fracture behavior. Mater Sci Eng A Struct Mater Prop Microstruct Process 558:170-174

44. Li SH, Liu LF, Yan JH et al (2014) An approach for testing and predicting longitudinal tensile modulus of 3D braided composites. J Reinf Plast Compos 33(8):775-784

45. Ouyang YW, Wang HL, Gu BH et al (2018) Experimental study on the bending fatigue behaviors of 3D five directional braided T-shaped composites. J Text Inst 109(5):603-613
46. Li DC, Fang DN, Jiang $N$ et al (2011) Finite element modeling of mechanical properties of 3D five-directional rectangular braided composites. Compos Part B 42(6):1373-1385

47. Tian Z, Yan Y, Luo H et al (2016) Parameterized unit-cell models for stiffness performance analyses of three-dimensional n-directional braided composites. J Reinf Plast Compos 35(19):1371-1386

48. Lu Z, Wang C, Xia B et al (2013) Effect of interfacial properties on the uniaxial tensile behavior of three-dimensional braided composites. Comput Mater Sci 79:547-557

49. Tian ZY, Yan Y, Li J et al (2018) Progressive damage and failure analysis of three-dimensional braided composites subjected to biaxial tension and compression. Compos Struct 185:496-507

50. Doan DD, Ramasso E, Placet $V$ et al (2015) An unsupervised pattern recognition approach for $A E$ data originating from fatigue tests on polymer-composite materials. Mech Syst Signal Process 64-65:465-478

51. Qi G, Wayne SF (2014) A framework of data-enabled science for evaluation of material damage based on acoustic emission. J Nondestruct Eval 33(4):597-615

52. Li J, Yao XF, Liu YH et al (2011) An analytic approach for the temperature and strain fields of composite laminate curing on a solid mold. Mech Adv Mater Struct 18(4):272-281

53. Zhang C, Xu XW, Chen K (2013) Application of three unit-cells models on mechanical analysis of 3D five-directional and full five-directional braided composites. Appl Compos Mater 20(5):803-825

54. Zhang DT, Sun Y, Wang XM et al (2015) Prediction of macromechanical properties of 3D braided composites based on fiber embedded matrix method. Compos Struct 134:393-408

55. Fang GD, Chen $\mathrm{CH}$, Yuan SG et al (2018) Micro-tomography based geometry modeling of three-dimensional braided composites. Appl Compos Mater 25(3):469-483

56. Zhang PF, Zhou W, Yin HF et al (2019) Progressive damage analysis of three-dimensional braided composites under flexural load by micro-CT and acoustic emission. Compos Struct 226:111196

Publisher's Note Springer Nature remains neutral with regard to jurisdictional claims in published maps and institutional affiliations. 